\title{
Can pupillometry diagnose a lack of analgesia prior to nursing in critically ill patients?
}

\author{
T Gaillard ${ }^{1 *}$, S Gergaud ${ }^{1}$, CM Grayot ${ }^{1}$, C François ${ }^{1}$, JF Hamel$^{2}$, S Lasocki ${ }^{1}$ \\ From ESICM LIVES 2015 \\ Berlin, Germany. 3-7 October 2015
}

\section{Introduction}

Patient's nursing is carried out several time per day in the intensive care. It is often described as painful by patients. The measurement of pupillary dilatation reflex (PDR) during a tetanic stimulation by pupillometry predicts analgesia level in the operating room and during tracheal aspirates in critically ill patients [1].

\section{Objectives}

The objective of this study is to evaluate whether this PDR predicts insufficient analgesia prior to a nursing care.

\section{Methods}

Prospective, interventional study conduct in an academic surgical ICU. After local ethic committee agreement and consent (relatives and patients)

Critically ill patients, intubated and mechanically ventilated, sedated, were included in the absence of ocular pathology, pace-maker, neuromuscular blockade agent, TBI or spinal cord injury. Before each nursing, the PDR was measured using a pupilometer (AlgiScan, IDMed France) during tetanic stimulation at increasing intensity $(5,10,20$, 40 and $60 \mathrm{~mA}$ ). The PPI score was also measured, it combines automated increasing tetanic stimulations with measurement of PDR, quoted in a scale ranging from 0 to 10 . During each nursing care pain was measured using the Behavorial Pain Scale (BPS). PDR values for each stimulation threshold and PPI score were compared for painful (BPS $>5$ ) and not painful $(\mathrm{BPS} \leq 5)$ nursing cares. The best diagnostic value was determined using ROC curves.

\section{Results}

Among the 170 nursings achieved in 41 patients (age $65 \pm$ 15 years, $33(80 \%)$ men, SAPSII $56 \pm 18,82 \%$ emergent

${ }^{1}$ Univ. Hospital Angers, Anesthésie Réanimation, Angers, France

Full list of author information is available at the end of the article surgeries, 5\% planned surgeries), 32 (18.8\%) were painful. Blood pressure during the nursing care were higher during painful nursings $(\mathrm{p}=0.02)$. But no other parameters were associated with pain during nursing (including the doses of sedation and analgesia). The areas under the curves of PDR at different stimulation levels did not exceed 0.6 (Figure 1), with no difference between the different intensity of stimulations. The PPI score was not better (4.1[3.2 to 5] vs 4.9[4.5 to 5.4] for painful or not, $\mathrm{p}=0.10$ ).

\section{Conclusions}

Pupillometry can not predict insufficient analgesia prior to a nursing care in surgical ICU patients. The heterogeneity of diseases (peritonitis, mediastinitis, multiple trauma, medical cause...) could explain these results, the same procedure (ie a nursing care) may induce an highly variable degree of pain depending on the patient conditions.

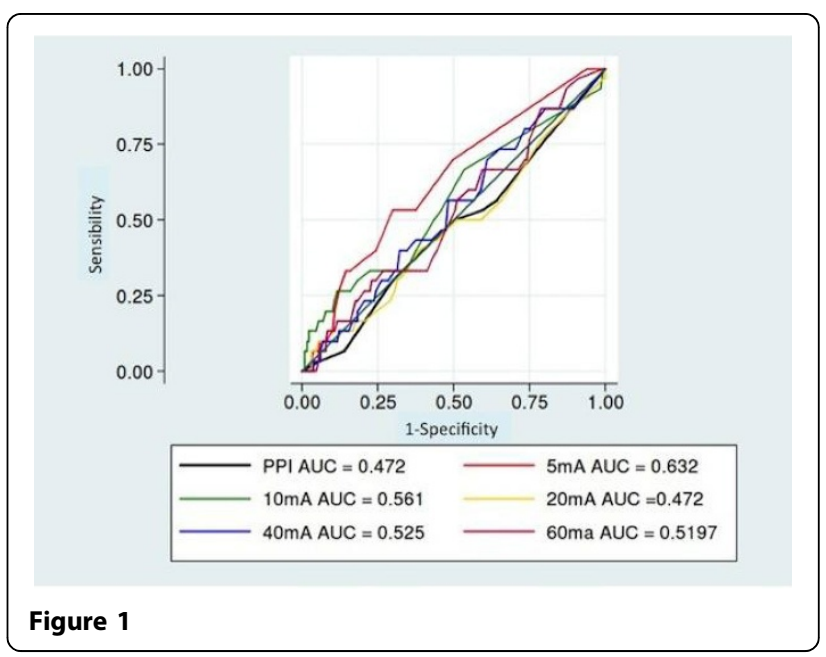

(c) 2015 Gaillard et al.; This is an Open Access article distributed under the terms of the Creative Commons Attribution License (http:// creativecommons.org/licenses/by/4.0), which permits unrestricted use, distribution, and reproduction in any medium, provided the original work is properly cited. 


\section{Authors' details}

${ }^{1}$ Univ. Hospital Angers, Anesthésie Réanimation, Angers, France. ${ }^{2}$ Univ.

Hospital Angers, Centre de Recherche Clinique, Angers, France.

Published: 1 October 2015

\section{Reference}

1. Critical Care 2013, 17:R161.

doi:10.1186/2197-425X-3-S1-A326

Cite this article as: Gaillard et al:: Can pupillometry diagnose a lack of analgesia prior to nursing in critically ill patients? Intensive Care Medicine Experimental 2015 3(Suppl 1):A326.

\section{Submit your manuscript to a SpringerOpen ${ }^{\circ}$ journal and benefit from:}

- Convenient online submission

- Rigorous peer review

- Immediate publication on acceptance

- Open access: articles freely available online

- High visibility within the field

- Retaining the copyright to your article

Submit your next manuscript at $\gg$ springeropen.com 